\title{
Design, construction, and beam tests of a rotatable collimator prototype for high-intensity and high-energy hadron accelerators
}

\author{
T. Markiewicz, E. Bong, L. Keller, and J. Smith \\ SLAC, Menlo Park, California 94025, USA
}

\author{
O. Aberle, C. Accettura, A. Bertarelli, E. Berthome, N. Biancacci, M. Butcher, F. Carra, \\ P. Gander, P. Gradassi, ${ }^{\ddagger}$ M. Guinchard, L. Lacny, A. Lafuente, J. Lendaro, \\ M. Pasquali, and S. Redaelli \\ CERN, CH-1211 Geneva 23, Switzerland \\ G. Valentino $0^{*}$ \\ University of Malta, Msida MSD2080, Malta
}

(Received 24 April 2019; revised manuscript received 28 November 2019; published 30 December 2019)

\begin{abstract}
A rotatable-jaw collimator design was conceived as a solution to recover from catastrophic beam impacts which would damage a collimator at the Large Hadron Collider (LHC) or its High-Luminosity upgrade (HL-LHC). One such rotatable collimator prototype was designed and built at SLAC and delivered to CERN for tests with LHC-type circulating beams in the Super Proton Synchrotron (SPS). This was followed by destructive tests at the dedicated High Radiation to Materials (HiRadMat) facility to validate the design and rotation functionality. An overview of the collimator design, together with results from tests without and with beam are presented.
\end{abstract}

DOI: 10.1103/PhysRevAccelBeams.22.123002

\section{INTRODUCTION}

The Large Hadron Collider (LHC) [1] at CERN is at the forefront of the energy frontier, designed to reach $7 \mathrm{TeV}$ per beam with a stored energy of $362 \mathrm{MJ}$. A High-Luminosity upgrade of the LHC, HL-LHC, is planned that will nearly double the stored beam energy [2]. Due to the potentially destructive nature of the circulating beams, the LHC is equipped with a multistage collimation system $[3,4]$, which removes halo particles before they can reach the machine aperture, possibly causing quenches of the superconducting magnets or radiation to electronics.

The LHC collimation system currently has a total of 108 collimators, mostly installed in insertion region (IR) IR3 and IR7 for off-momentum and betatron cleaning, respectively. The collimator jaws are positioned at various gaps around the beam center in order to form a hierarchy, with

\footnotetext{
*gianluca.valentino@um.edu.mt

Present address: NASA Ames Research Center, Moffett Field, California 94035, USA.

Present address: A.D.A.M. Applications of Detectors and Accelerators to Medicine, CH-1211 Geneva 23, Switzerland.

Published by the American Physical Society under the terms of the Creative Commons Attribution 4.0 International license. Further distribution of this work must maintain attribution to the author(s) and the published article's title, journal citation, and DOI.
}

the primary collimators (TCP) being closest to the beam edge, followed by the secondary collimators (TCSG), tertiary collimators (TCTP), and absorbers (TCLA). Other collimators are used for injection protection (TCLI/TDI), dump protection (TCDQ/TCSP) or luminosity debris protection (TCL) purposes. The TCP and TCSG collimators and the protection devices that are the closest to the beam are made of carbon-based active materials whereas other collimators are made of a tungsten heavy alloy. In the betatron cleaning region in IR7, the collimation system must absorb approximately $90 \mathrm{~kW}$ from the primary collimators in a 1 hour beam lifetime and $500 \mathrm{~kW}$ during a $10 \mathrm{~s}$ transient loss condition [3]. In addition, the carbon secondary collimators dominate the impedance budget of the LHC. These numbers nearly double for HL-LHC.

Prior to the LHC start-up in 2008, work had already commenced on an upgrade of the collimation system, which would foresee the deployment of low-impedance collimators capable of withstanding beam impacts [5] while overcoming the high impedance of the present primary and secondary collimators. This led to the concept of a collimator whose jaws could rotate in the event of catastrophic damage, therefore presenting a fresh collimating surface instead of requiring a lengthy replacement. The design failure scenario considered was that of an asynchronous beam dump at $7 \mathrm{TeV}$, in which there is a spontaneous firing of one out of 15 dump kicker magnets, causing beam to receive a kick in the horizontal plane, which results in impacts with the machine 
aperture rather than a normal progression through the dump line. It was estimated that 8 bunches, corresponding to $1 \mathrm{MJ}$ of energy, could impact one of the secondary collimators in IR7. Therefore, these rotatable collimators would be installed in these locations in the LHC. This scenario has been revised since then (see e.g., [6-8]) by more realistic models, but is still relevant for design specifications of IR7 collimators.

A rotatable collimator prototype was developed at SLAC and delivered to CERN in 2013 for beam tests in the Super Proton Synchrotron (SPS) and the High Radiation to Materials (HiRadMat) test facility [9]. The prototype was foreseen as a possible option for the HL-LHC, and was supported by the US-LARP collaboration. The tests with circulating beam at the SPS were done to check the performance of the prototype with respect to standard LHC collimators, such as during beam-based alignment, and to measure its impedance contribution. On the other hand, the destructive tests performed at HiRadMat had the scope of evaluating the performance of the rotation mechanism for different levels of beam impact.

This paper first introduces the rotatable collimator design, and then gives an overview of the validation tests done without beam (also reported in [10]). This is followed by the tests and results obtained with circulating beam in the SPS, and the beam damage experiment (HRMT-21) performed at the HiRadMat facility at CERN.

\section{ROTATABLE COLLIMATOR DESIGN}

\section{A. Key design concepts}

A major portion of the preliminary design effort was directed at identifying materials and jaw geometries which would produce the best collimation efficiency, meet the $25 \mu \mathrm{m}$ flatness specification for the collimation surface, and be able to be cooled with a reasonable water flow in both the steady state and transient conditions.

Early work at CERN, then repeated at SLAC, showed that to maximize absorption high-Z materials are preferable. Extensive FLUKA and ANSYS simulations of energy deposition and mechanical deformations were performed for a wide variety of materials, including copper, Inconel, titanium, tungsten, aluminum, and $\mathrm{BeCu}$. Ultimately, copper was selected as the material providing the best balance of collimation efficiency, low thermal distortion and manufacturability [11].

The rotatable collimator design features two cylindrical jaws, each of $1 \mathrm{~m}$ length, designed to each absorb $12 \mathrm{~kW}$ of beam in steady state and up to $60 \mathrm{~kW}$ in transitory beam loss with no damage and minimal thermal distortion [12]. In comparison, each of the present carbon-based TCSGs can absorb up to $30 \mathrm{~kW}$ for the $500 \mathrm{~kW}$ beam loss scenario (which corresponds to a beam lifetime of $0.2 \mathrm{~h}$ and is expected to last up to $10 \mathrm{~s}$ ) [1]. Each jaw has 20 facets, and is made of Glidcop®, which is an alumina-strengthened

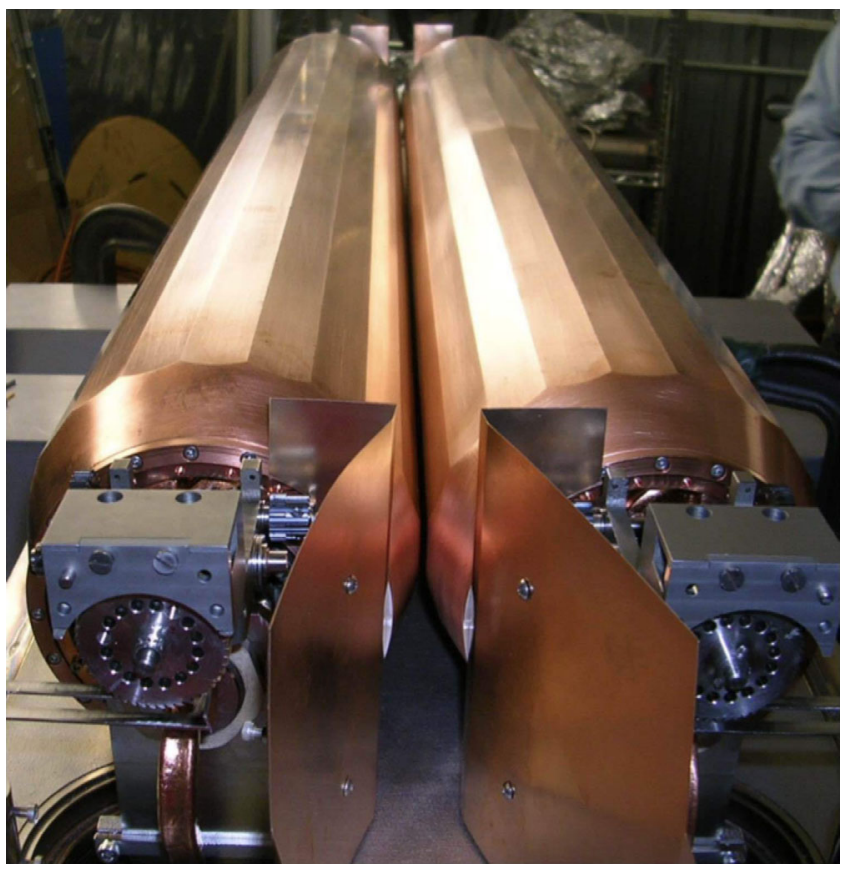

FIG. 1. Beam view of the rotatable collimator prototype with the tank removed.

copper alloy. The beam view of the collimator jaws is shown in Fig. 1. The design is motivated by the use of a radiation resistant, high-Z, low-impedance readily available material. A vacuum rotation mechanism using the standard LHC collimation jaw positioning motor system allows each jaw to be rotated to present a new $2 \mathrm{~cm}$ high surface to the beam if the jaw surface were to be damaged by multiple full intensity beam bunch impacts in an asynchronous beam abort.

\section{B. Jaw translation and rotation}

The collimator uses the same stepping motor drive system as the collimators presently installed in the LHC. Motors $\mathrm{A}$ and $\mathrm{C}$ on the upstream and downstream corners of the left (beam's eye view) and right (B and D) collimator jaws translate each corner independently. The upstream and downstream jaw gaps are denoted as $\mathrm{AB}$ and $\mathrm{CD}$, respectively. An independent read-out of the jaw positions is provided through six linear variable differential transformers (LVDTs), one per each jaw corner and one per jaw gap ( $\mathrm{AB}$ and $\mathrm{CD}$ ).

The jaw is rotated through a ratchet and pawl mechanism, which is driven by a claw engaging the ratchet when the jaw overtravels. The mechanism is shown in Fig. 2. The rotation actuator engages the drive wheel only when a jaw is rotated beyond any position where it may be used in normal operation ( $>5 \mathrm{~mm}$ past the beam line). This requires the inner switch, which would otherwise stop the jaw to prevent it from hitting a hard mechanical limit, to be disabled via software during this time. 


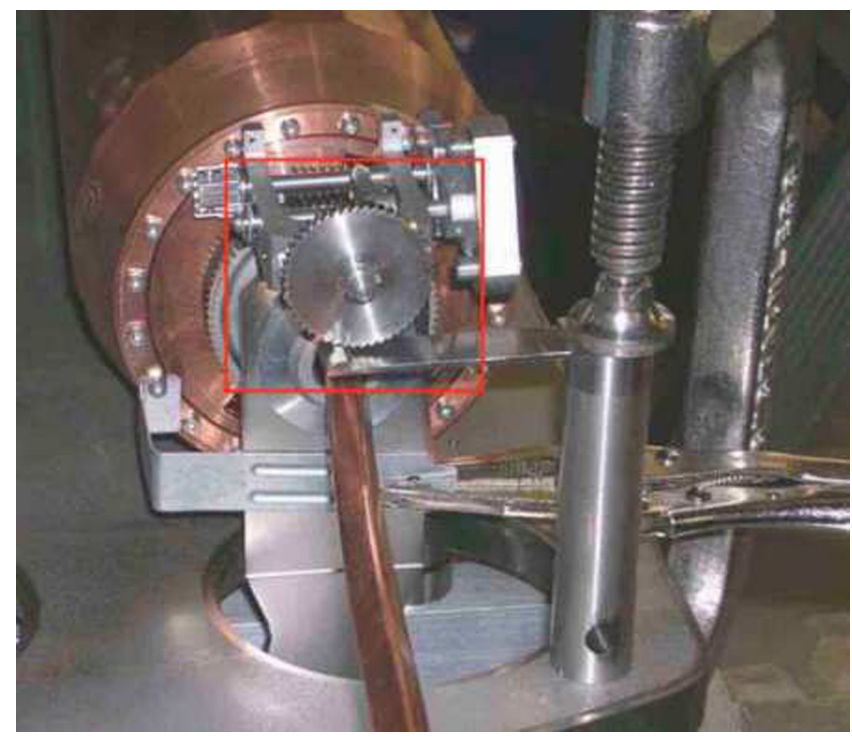

FIG. 2. View of the rotation mechanism (inside red box) attached to the jaw mounted on the base plate.

The left and right jaws rotate clockwise and anticlockwise, respectively. Eight full revolutions of the 48-teeth ratchet are required to rotate the jaw by one facet, which corresponds to $1 / 20$ th of a revolution. A full facet rotation requires approximately 1.5 hours to be completed. A schematic of the rotatable collimator prototype, showing the location of the rotation mechanism, motors and LVDTs is shown in Fig. 3.

\section{Considerations of impedance effects}

There are two main contributors to the total collimator impedance: resistive-wall impedance and geometric

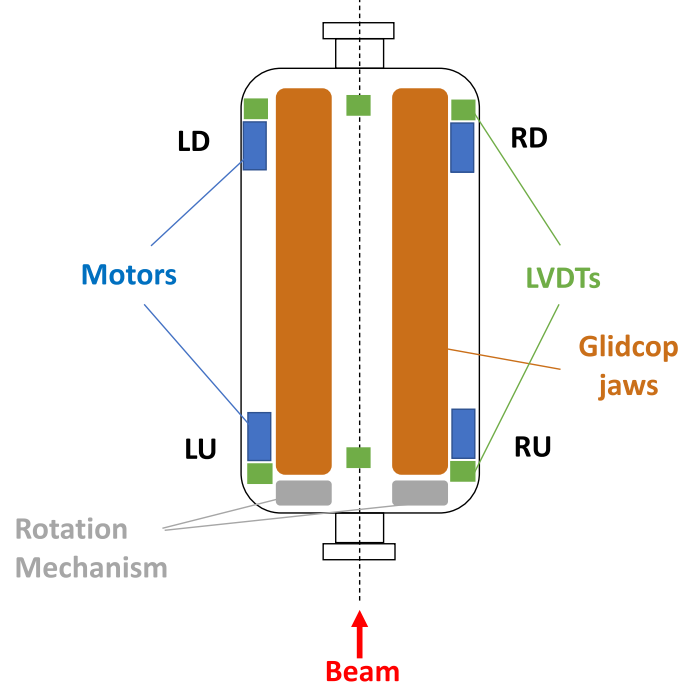

FIG. 3. Rotatable collimator coordinate system, where leftupstream $(\mathrm{LU})=$ corner $\mathrm{A}$, right-upstream $(\mathrm{RU})=$ corner $\mathrm{B}$, leftdownstream $(\mathrm{LD})=$ corner $\mathrm{C}$ and right-downstream $(\mathrm{RD})=$ corner D.

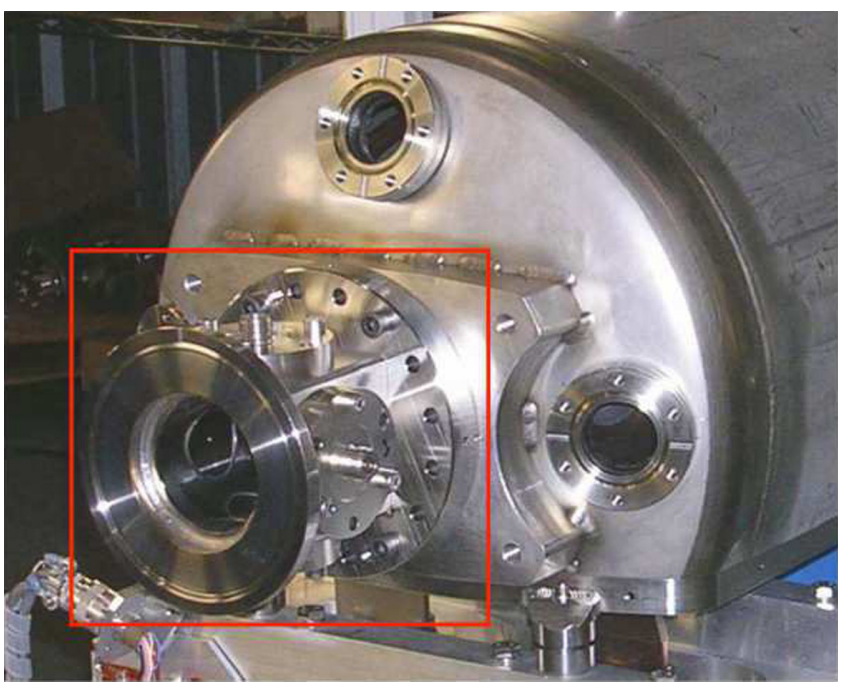

FIG. 4. BPM attached to one side of the prototype collimator tank (inside red box).

impedance. The resistive-wall impedance is mainly related to the copper jaws. With this in mind, the target impedance design goal is to ensure that the design presents an impedance which is as small as possible in comparison to the total impedance budget of the machine in which the installation is foreseen. The geometric impedance is driven by the taper at each end of the collimator. Using the standard Yokoya collimator impedance formulas [13] the kick-factor contribution from both the resistive wall and geometric was calculated. The taper length was optimized to maximize the jaw length and still be in the shadow of the jaw resistive wall impedance. The sliding contact between the rotating jaw and the stationary rf foil must also have a low-contact resistance in order to allow for a smooth path for the image currents.

So-called rf bearings on the outer ends of the jaws, allow, despite jaw rotation, $\mathrm{BeCu}$ foils to be held fixed in place to provide a smoothly varying low-impedance path for image currents to pass from the collimator jaws to the vacuum tank. The present design uses captured ceramic balls in stainless races. Rather than relying on the balls themselves to provide a low-impedance path, a rhodiumcoated $\mathrm{BeCu}$ corrugated sheet is placed between the foils and the jaw. Further details on the impedance design are present in $[14,15]$.

\section{Beam instrumentation}

The prototype is equipped with beam position monitors (BPMs) on the upbeam and downbeam sides, as shown in Fig. 4. Each device is a standard LHC-type BPM with a diameter of $37 \mathrm{~mm}$, and consists of four pick-up buttons, which can measure the beam trajectory in both horizontal and vertical planes. The BPM pick-up buttons are rigid, contrary to the novel embedded BPM design already present in $\sim 18 \%$ of the LHC collimators [16], which are 
TABLE I. Summary of key design specifications of the rotatable collimator prototype.

\begin{tabular}{lc}
\hline \hline Parameter & Value \\
\hline Dimensions LxWxH (with BPMs) & $1.48 \times 0.43 \times 0.63275 \mathrm{~m}$ \\
Jaw length & $1 \mathrm{~m}$ \\
Jaw flatness & $25 \mu \mathrm{m}$ \\
Jaw material & Glidcop® \\
Electrical resistivity & $0.02 \mu \Omega \mathrm{m}$ \\
Vacuum & $7.5 \times 10^{-10}$ Torr \\
Rotation speed & 1.5 hours/facet \\
\hline \hline
\end{tabular}

installed in the jaw tapering and therefore move with the jaw. The goal is to aid in positioning the jaws correctly with respect to the closed orbit, with a resolution of $25 \mu \mathrm{m}$ or better [15]. A summary of the key design parameters and specifications is shown in Table I.

\section{PROTOTYPE VALIDATION WITHOUT BEAM}

\section{A. Validation tests done at SLAC}

As described in $[11,17,18]$, when the collimator jaws are mounted for the final time on their supports, each cooling tube stub is given a $90^{\circ}$ bend so that it can project through and be brazed to a copper vacuum feedthrough at the base of the bellows that is driven by the stepping motor system. The tube winding has been arranged so that each tube end leaves the mandrel at the end of the jaw opposite to where it exits via the feedthrough. The resulting $\sim 1 \mathrm{~m}$ of free length, carried in the hollow mandrel support cylinder, allows the copper tube to twist the $360^{\circ}$ required to expose each of the 20 jaw facets to beam and avoids any water-tovacuum braze.

Before the tubes were so constrained, the rotation drive mechanism was qualified and $\mathrm{rf}$ foil contact resistance measured. After verifying that each jaw could freely rotate with minimal friction on its bearings, and that each of the two rotation drives functioned as designed, an artificial torsional load of $\sim 30 \mathrm{Nm} \mathrm{Nm}$ was applied and the drives retested for a facet rotation $\left(18^{\circ}\right)$ under load. Coil twisting tests indicated that this was 10 times the torque required to twist $1 \mathrm{~m}$ of tubing 1 full turn and 4 times the torque required to put 4 full twists into the tube. This was considered as an appropriate design margin for the operation in the machine.

The two jaws installed in the prototype had flatness and diameter verified on a granite table with dial indicators. After setting the upper facets to be parallel, it was verified that the facets facing the beam were also parallel for each rotational position of the jaws. As the jaws were rotated, a 4-wire resistance bridge was used to verify that the contact resistance between each end of each $\mathrm{BeCu}$ foil and the jaw surface was 1-2 mOhm. Before sealing the collimator in its vacuum tank, a coordinate-measuring machine (CMM) measured the jaw positions relative to external tooling balls.
For this prototype, two $\sim 2 \mathrm{~cm}$ wide, $2 \mathrm{~mm}$ thick flanges had been welded to the vacuum baseplate and to the cylinder-shaped vacuum cover. Welding was first mechanically simulated by clamping these flanges together. Upstream-to-downstream foil resistance and length, thermistor functionality, and proper movement of the foils during the rotation operation were verified; these tests led to the installation of the height adjustment system for the actuator.

The vacuum seal was achieved by edge welding the two wide flat flanges together and by brazing the copper water cooling tubes to their feedthroughs. The edge weld can be easily ground away if access to the tank interior is later desired; the flange is wide enough such that several rewelds are possible. Vacuum processing included leak testing, the finding and sealing of several pinhole leaks and, in lieu of baking, several hours of cleaning with $\mathrm{O}_{2}$ and $\mathrm{H}_{2}$ plasmas. The end vacuum result showed an acceptable residual gas analysis (RGA) scan and $3 \times 10^{-8}$ Torr at the RGA input.

A correct full-facet rotation of each jaw was verified after the tank was welded and a second full facet test rotation of each jaw was verified in vacuum. Each tube was leak checked after every assembly procedure of this device, and no leak could be seen at the $1 \times 10^{-13}$ torr-l/s sensitivity of the tester. LHC-style water fittings were brazed to the tube ends and flow and pressure tests made. At 3.5 bar operating pressure, flow was measured to be $8 \mathrm{l} / \mathrm{min}$, with a pressure drop of 2.8 bar. Each tube was subjected to a static pressure test of 24 bar. Finally, the tubes were blown try and again leak tested. Acrylonitrile butadiene styrene (ABS) plastic parts from a 3D printer, to block the jaws for air transport, were made, cleaned, vacuum pumped, wrapped in foil, and blocked in place to prevent jaw movement during air transport to CERN.

\section{B. Validation tests done at CERN}

In order to ensure compliance with installation in the SPS, vacuum leak tightness tests were performed on the collimator. The leak tightness test consists of two steps. During a first step, a pumping system creates a vacuum inside the collimator after which, in a second step, some nitrogen is sprayed locally around the sensitive parts of the collimator in order to check for an eventual leak. This test is usually carried out right before the bake-out and residual gas analysis test, but it was decided to anticipate it in order to further assess the collimator's good condition and at the same time take advantage of it to test some spare parts (mainly spare flanges) that had been shipped separately from the collimator. Several possible configurations of the collimator were tested. The 6" plain flanges were replaced by some BPM flanges that were installed with some helicoflex ${ }^{\circledR}$ seals and the collimator was tested with two types of 2.75" flanges: plain flanges and windowed flanges. Both configurations succeeded the tests as no leak was detected and they both reached a vacuum level in the order of $7.5 \times 10^{-10}$ Torr. Finally, the configuration with windowed 

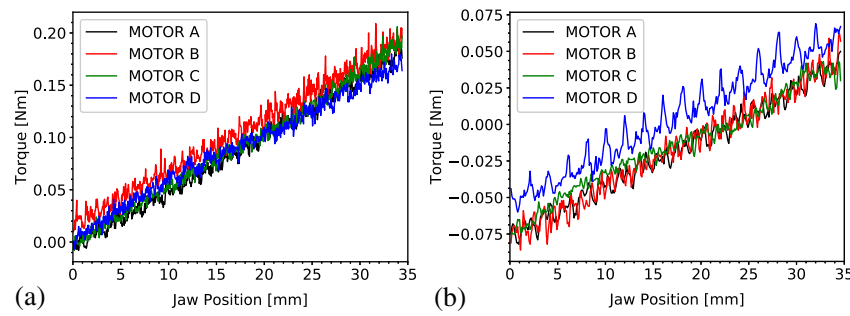

FIG. 5. Static and dynamic torque measurements for the four jaw motors. (a) Static torque and (b) Dynamic torque (IN to OUT).

flanges was selected for the later bake-out and out-gassing test as it is the favorite candidate for the installation. An outgassing rate of $2.7 \times 10^{-8} \mathrm{mbar} 1 / \mathrm{s}$ was measured, which is well below the acceptable rate of $2 \times 10^{-7} \mathrm{mbar} 1 / \mathrm{s}$ for installation in the LHC.

A first series of impedance tests were then performed in order to determine whether the design matched the initial specifications and was compatible, in full open position, with the high-intensity operations in the SPS. The collimator was measured with single wire and probe measurements. The observed modes (between $90 \mathrm{MHz}$ and $200 \mathrm{MHz}$ ) are in good agreement with the previously computed ones $[15,19]$.

Drive mechanism tests were necessary to ensure that the prototype could be operated like a standard LHC collimator. Several jaw translation movements were performed to measure LVDT calibration, mechanical play, and the motor torque. The collimator was connected to a controls test stand equipped with a PXI chassis. Torque measurements were done via an automatic scan procedure developed for the acceptance of the standard LHC collimators, and are plotted in Fig. 5. The measurement of the static and dynamic torque during movement has been identified as an effective test to detect defects of the material or of the assembly procedure; in particular it can easily detect hard points or eccentricity of the kinematic chain, by measuring peaks or oscillations of the torque value during the measurement. The static torque is the peak torque which can be applied to the shaft of an energized motor at standstill, whereas the dynamic torque is the torque developed by a motor at low stepping rates. The dynamic torque was measured by performing jaw movements from the inner to the outer switches, while the static torque was measured through $50 \mu \mathrm{m}$ jaw step movements. The maximum torque $(\sim 0.4 \mathrm{Nm})$ compares well to the LHC requirement of $0.5 \mathrm{Nm}$ [20], and as expected there is a linear increase in the torque with jaw position due to the return springs which automatically retract the jaws to parking positions in the event of a power failure.

Measurements of the mechanical play are shown in Fig. 6. The values obtained are below $20 \mu \mathrm{m}$ and compare well to the LHC specifications. The built-in nonlinearity of the LVDTs was measured as shown in Fig. 7. The nonlinearities are due to the way the internal coils are wired inside the LVDT, and is acceptable up to $0.2 \%$ over the jaw

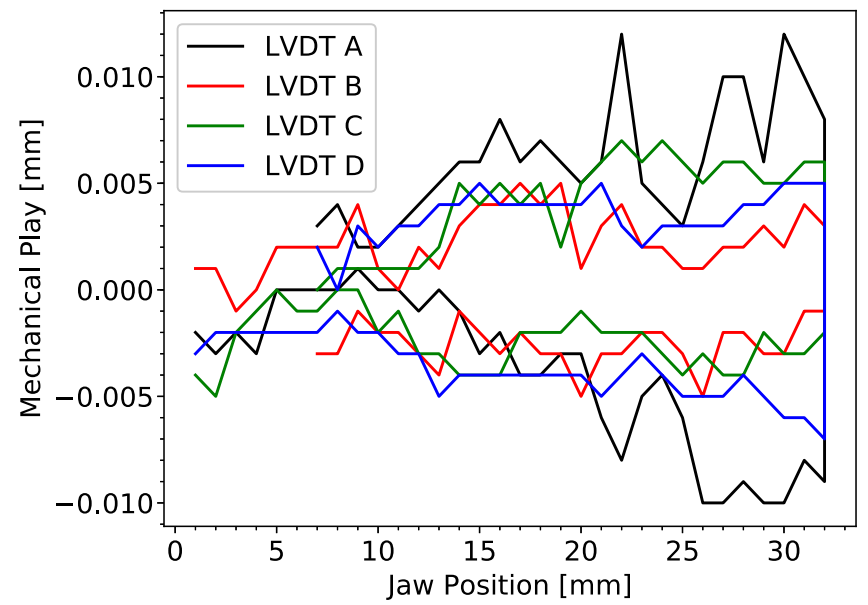

FIG. 6. Residual LVDT readings for the four collimator axes, subtracted from the absolute position, for a full-in/full-out jaw movement, indicating mechanical plays of at most $20 \mu \mathrm{m}$ over a $30 \mathrm{~mm}$ stroke.

movement range. For operational purposes, a look-up table obtained from metrology measurements will be used to calibrate the LVDT readings. In addition, in the event of a power cut to the motors, the collimator jaws are designed to automatically retract to parking positions to prevent uncontrolled movements into the beam. This was tested successfully by switching off the controls test stand connected to the collimator.

Finally, jaw rotation tests were performed. As in the prototype, no automatic readout of the jaw rotation is available, and the rotation of the wheel and number of steps executed were verified visually by lifting the rf foil. A less precise, though less invasive indication of the jaw rotation
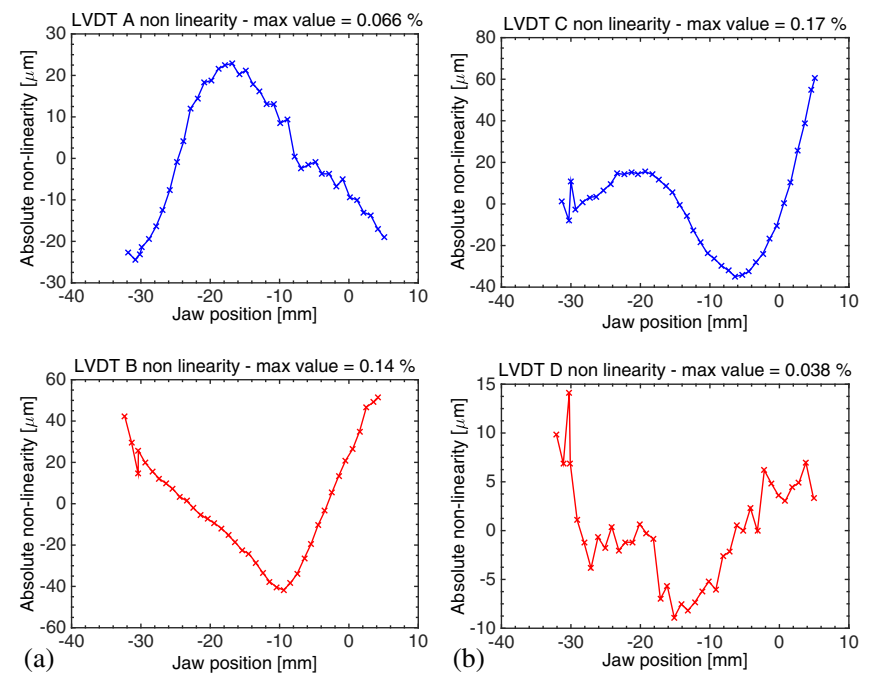

FIG. 7. Differences measured in the LVDT position (nonlinearities) with respect to the collimator jaw motor positions over the full range of movement. (a) Nonlinearity A and B and (b) Nonlinearity C and D. 
can be obtained by observing inscribed lines on the jaw surface, which are visible through portholes. At CERN, one full facet rotation of both jaws was performed successfully. The claw needed to be tightened to prevent the ratchet from missing steps mid-way through the facet rotation.

While the rotation drive mechanism used here is adequate in a prototype device, before using the rotatable collimator in an operating accelerator, a second generation rotation drive should be developed, emphasizing robustness and incorporating an indexing scheme for angular position readout.

\section{PERFORMANCE WITH CIRCULATING BEAMS AT THE CERN SPS}

\section{A. Experimental apparatus}

Following surface validation tests at CERN, the rotatable collimator prototype was installed in the horizontal plane during a Technical Stop in June 2015 in Long Straight Section (LSS) 5 of the SPS, and assigned the layout name TCRMP (Target Collimator Rotatable Metallic Prototype). The installation profited from the existing infrastructure for the test stand used for the BPM collimator demonstrator [21]. An existing LHC-type ionization chamber beam loss monitor (BLM) was moved to be closer to the collimator to record the localized beam losses generated when the jaws are inserted into the beam.

The collimator was connected to the beam interlock system, with the strategy that an interlock is triggered when one of the jaw corners leaves the garage position's switches (around $\pm 30 \mathrm{~mm}$ ). This interlock was masked in our beam tests and kept operational for the standard SPS operations. The collimator was also integrated into the standard LHC collimator control software environment [22], in which movement commands can be sent from a Java graphical user interface (GUI) to the front-end software architecture (FESA) [23] middleware layer, which then sends and receives position data to and from the PXI modules.

Beam tests related to collimator beam-based alignment, BPM performance and impedance measurements were performed at the SPS over a two-day period in August 2015. Unless otherwise specified, the tests were done with one nominal LHC-type bunch with an intensity of $1.1 \times 10^{11}$ protons at an energy of $55 \mathrm{GeV}$. At the installation location of the TCRMP, $\beta_{h}=26.83 \mathrm{~m}$ (Q26 optics), giving a horizontal $1 \sigma$ beam size of $1.266 \mathrm{~mm}$ at $55 \mathrm{GeV}$. The horizontal dispersion function is close to zero.

\section{B. Fixed-aperture BPM performance}

The BPM pick-ups at the upstream and downstream sides of the collimator were connected to the Diode ORbit and OScillation (DOROS) [24] readout electronics, which convert nanosecond pulses from the pick-ups into slowly varying signals, which are then low-pass filtered and sent to a 24-bit analog-to-digital converter (ADC) with a sampling
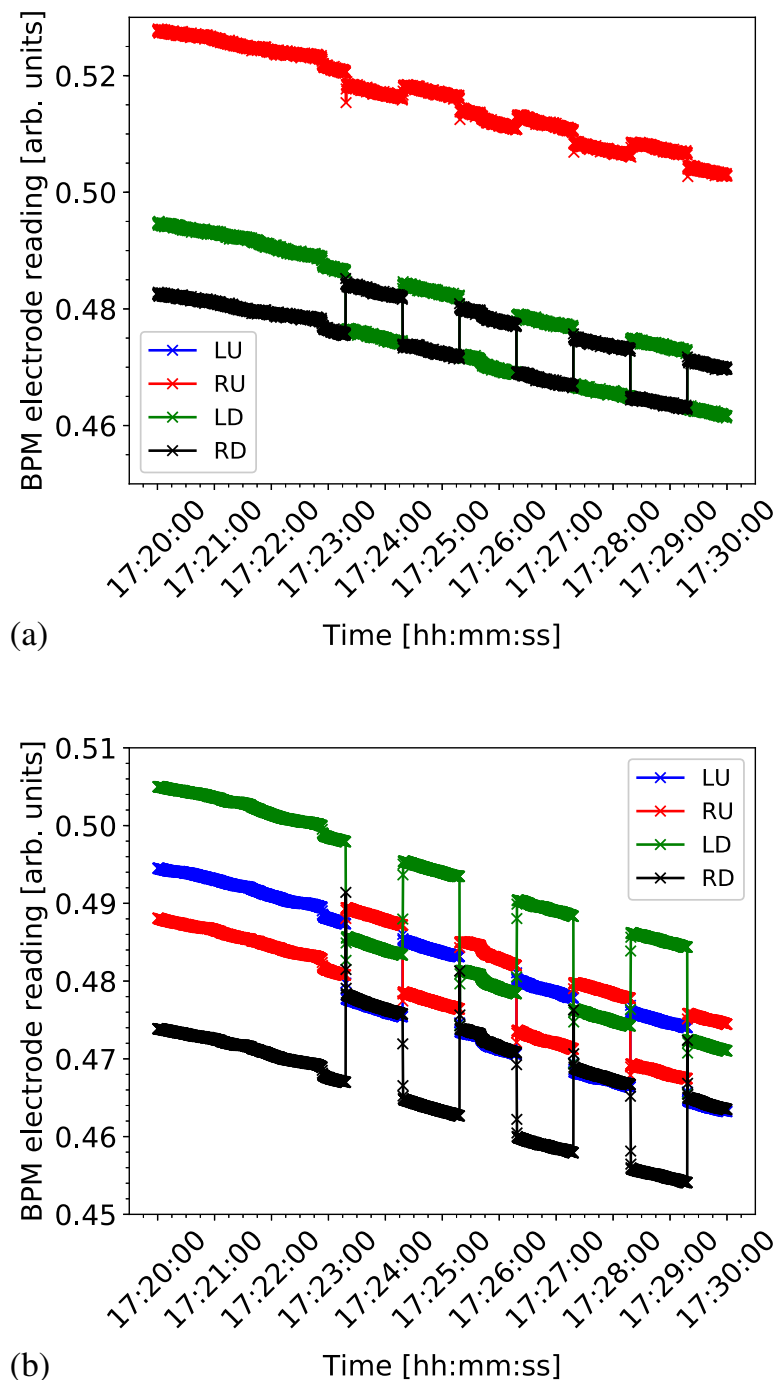

FIG. 8. The BPM pick-up signals during the electronics calibration test, during which the BPM channels are inverted seven times. The slight decrease in the signal amplitudes over time is due to the intensity decrease from normal beam losses. (a) Horizontal BPM and (b) Vertical BPM.

frequency of a few $\mathrm{kHz}$. This allows submicrometer beam position resolution to be achieved.

In order to correct for the asymmetries between the cables and the electronics, the BPM signals were inverted in an established calibration procedure [25] to obtain gain and offset correction coefficients for the readout electronics. Measurements obtained during the beam tests at the SPS for both the horizontal and vertical BPMs are shown in Fig. 8. In the absence of asymmetries, it would not be possible to distinguish between the two configurations (inverted and noninverted). The coefficients were only deployed for the remainder of the beam tests for the vertical BPMs, for which a change of $2 \%$ was recorded in the signal between the two configurations. This is similar to what was measured with the LHC-type BPM collimator prototype. 


\section{Beam-based alignment}

The beam center at the rotatable collimator prototype was determined using a well-established beam-based alignment procedure used for the standard LHC collimators with circulating beam [26]. In this procedure, each jaw is moved in steps of $100 \mu \mathrm{m}$ (larger steps than what is normally used in the LHC due to the large beam size in the SPS) until a spike is observed in the signal of the BLM positioned near the collimator. Once both jaws have touched the beam on either side, the beam center can be calculated as the average of the two aligned jaw positions.

An example of an alignment performed during the beam test is shown in Fig. 9. In this measurement, both jaws were kept parallel to the nominal central orbit, i.e., the motors of each jaw were kept at the same settings. The aligned position as found with the BLM method corresponds to average horizontal readings of about $500 \mu \mathrm{m}$ (bottom graph of Fig. 9). This is a static offset that could be caused by errors in the BPM mounting or by alignment errors of the whole collimator tank.

In order to evaluate the reproducibility of the alignment technique and the correct acquisition of the BPMs, a series of horizontal orbit bumps with increasing amplitudes were placed. For each orbit bump, the collimator BPM measurement was recorded and the collimator was realigned using the BLM-based technique. The results are shown in Fig. 10. There is a good relative comparison
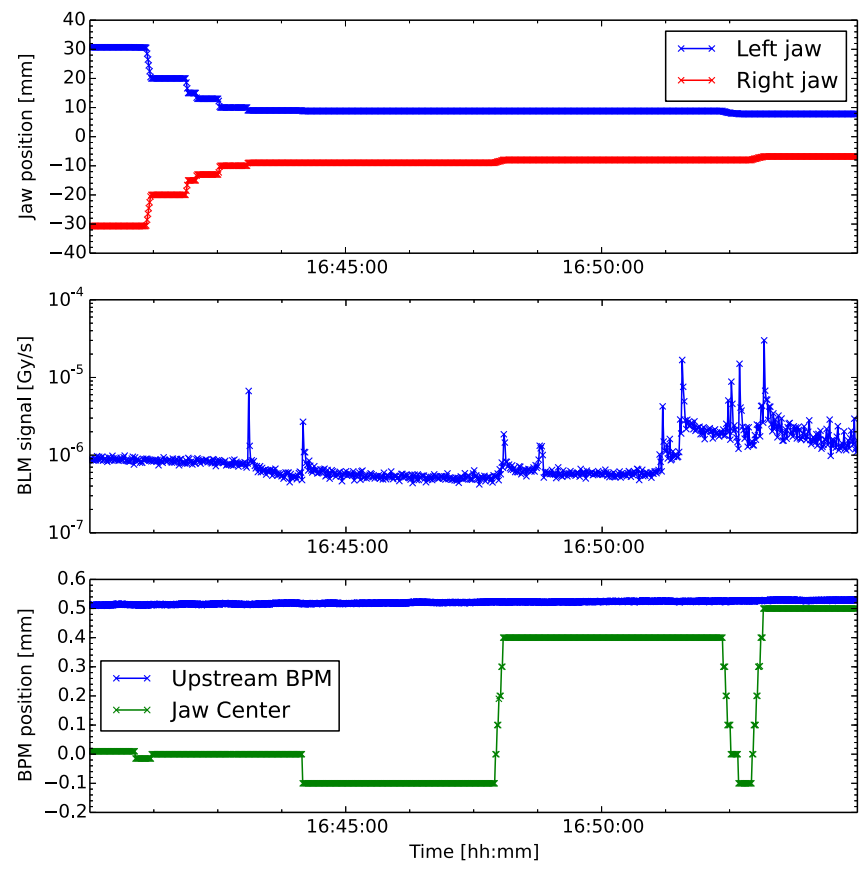

FIG. 9. Beam-based alignment of the rotatable collimator prototype, showing the left and right jaw positions (top), the recorded BLM signal (middle), and a comparison of the collimator center to the beam position measured by the upstream BPM (bottom) as a function of time.

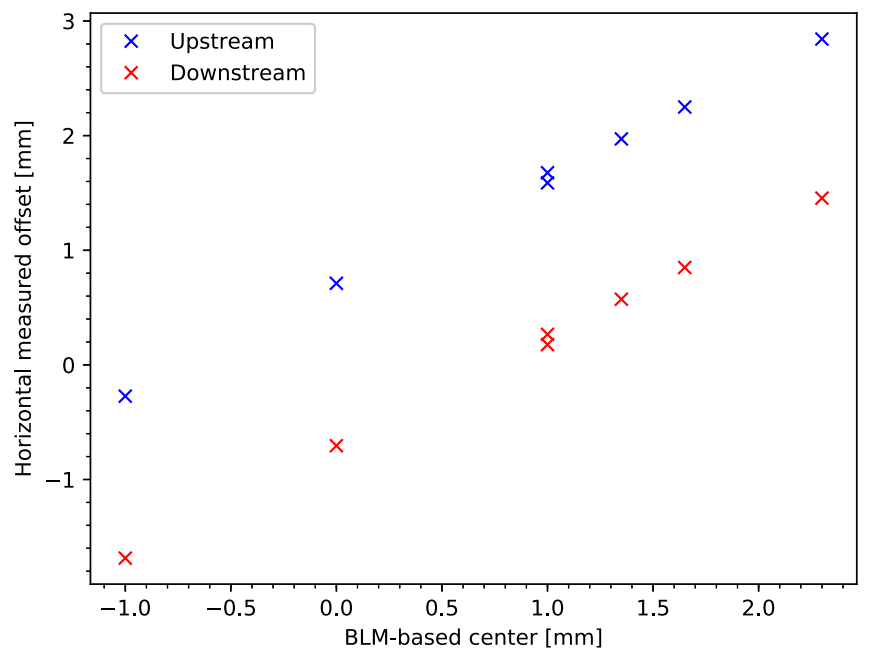

FIG. 10. The horizontal beam offset measured by the BPMs as a function of the beam center measured by the BLM-based technique for different shifts of the local closed orbit.

between the two measurements, however a $1.5 \mathrm{~mm}$ difference is apparent between the upstream and downstream BPM readings. An individual BLM-based jaw corner alignment with the horizontal orbit bump removed resulted in an upstream center of $-0.7 \mathrm{~mm}$, and a downstream center of $-1.15 \mathrm{~mm}$, therefore confirming the presence of a tilt in the collimator tank along the longitudinal axis. This was later confirmed by an alignment survey in the SPS tunnel.

The collimator was then realigned using the beambased technique for different vertical beam orbit bumps in the range of $\pm 10 \mathrm{~mm}$, to evaluate whether any change in the measured beam center would be registered, given that the jaw facet height is $20 \mathrm{~mm}$. The variations in the horizontal measured offset were within the expected range given the large range of vertical bumps applied, and compatible with the expected orbit reproducibility at the SPS.

In addition, similar as is done for the standard LHC collimators, the beam size at the rotatable collimator prototype was also measured. As this measurement requires a reference collimator, another double-sided collimator (TCSM.51934) installed close by [21] was used. A measuredto-nominal beam size ratio of $120 \%$ was obtained, which is comparable to what is achieved with LHC collimators. The unique jaw design did not adversely impact the beam based alignment of the collimator.

\section{Impedance measurements with high bunch intensities}

Prior to the beam tests, analytical studies of the dipolar impedance of $2 \mathrm{D}$ infinitely extended parallel copper plates as a function of jaw gap were performed using the Impedancewake2D code [27]. This code assumes a multilayered parallel plate geometry and solves field matching 
equations to obtain the beam coupling impedance from the resistive wall. This is used as direct input for the tune shift computations, neglecting the geometric impedance due to the tapering and found to be negligible. We assumed two jaws of $25 \mathrm{~mm}$ copper ( $17 \mathrm{n} \Omega \mathrm{m}$ resistivity) with variable half gap. The boundary condition is infinite vacuum. The results give an expected horizontal tune shift of $4 \times 10^{-8}$ at the operational half-gap of $5 \mathrm{~mm}$ at $55 \mathrm{GeV}$, as shown in Fig. 11.

The impedance measurements were performed in the SPS at $55 \mathrm{GeV}$ and $270 \mathrm{GeV}$. An instability with azimuthal mode $m=+1$ was systematically observed when scraping at full gap of less than $10 \mathrm{~mm}$ (corresponding to a half-gap of $\sim 4 \sigma$ ) at $55 \mathrm{GeV}$. This could be due to a loss of Landau damping due to emittance reduction as the collimator jaw was moved into the beam. From the measurements taken at $270 \mathrm{GeV}$ it was observed that there is no measurable variation of the tune correlated with the moving gap. Therefore, in both cases the beam tests show that resistive wall impedance is small and at least below the measurement resolution $\left(\Delta Q \sim 10^{-4}\right)$.

The analytical calculations were performed with the typical single bunch intensity of $1.3 \times 10^{11} \mathrm{p}$. During the experiment, the intensity available was $\sim 25 \%$ higher allowing for a corresponding $\sim 25 \%$ larger tune shift. Nonetheless, the expected tune shift remains in the range of $4 \times 10^{-8}$. The accuracy required to measure such a small tune shift is not compatible with the machine tune reproducibility (fluctuations were in the order of $\sim 1 \times 10^{-4}$ ). In order to enhance the tune shift, the measurement was performed at $55 \mathrm{GeV}$ as this is the lowest allowed energy in the SPS compatible with machine operation. Measurements at higher energy $(270 \mathrm{GeV})$ where also done for completeness, where a reduction of a factor 5 is expected in the tune shift.

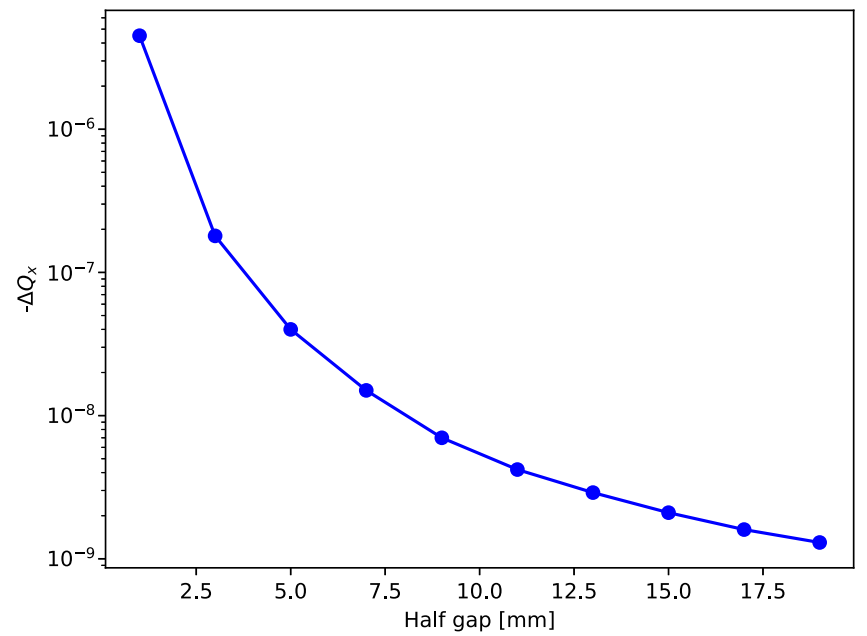

FIG. 11. Estimated horizontal tune shift from the mode $m=0$ as a function of jaw half gap at $55 \mathrm{GeV}$ for a bunch charge of $1.3 \times 10^{11}$ protons and a bunch length of $\tau_{b}=4 \sigma_{\mathrm{rms}}=3 \mathrm{~ns}$.

\section{BEAM DAMAGE TESTS AT THE CERN HIRADMAT FACILITY}

\section{A. Experimental setup}

The CERN HiRadMat facility allows for destructive testing of accelerator components, including collimators $[28,29]$ and novel materials [30,31]. It takes proton (or heavy ion) beams from the SPS at a maximum energy of $440 \mathrm{GeV}$, in a train of up to 288 bunches. The beam damage tests on the rotatable collimator prototype (called experiment HRMT-21) were carried out in July 2017. Then, each bunch could have up to $1.7 \times 10^{11}$ protons, giving a total pulse energy of 3.4 MJ. The 1- $\sigma$ transverse normalized emittance could be controlled between 2-4 $\mu \mathrm{m}$.

The primary goal of the HRMT-21 experiment was to demonstrate that the rotation functionality could survive a beam impact at top energy, i.e., an asynchronous beam dump with an impact of 8 bunches at $7 \mathrm{TeV}$. Due to the higher beam intensity available at the HiRadMat facility, this was extended to understand the onset of damage for even more demanding scenarios, such as the LHC injection error, in which 288 bunches at $450 \mathrm{GeV}$ could impact a collimator. On the other hand, the intensity available at HiRadMat is lower than the HL-LHC injection error scenario, so the equivalence in this case was done in terms of energy density and not momentum. Other goals were to ensure the integrity of the cooling pipes under both beam impacts and jaw rotation, to compare the debris pattern of the ejecta relative to the $2 \mathrm{~cm}$ facet width, and to check for any welding of the jaws by the ejecta when they are separated by nominal LHC-type jaw aperture. After radiation cool down the vacuum tank will be opened, the jaws removed, and jaw flatness measured for permanent deformation.

The collimator was placed on a table installed in the HiRadMat tunnel, which is in the SPS BA7 area, a few metres upstream from the beam dump. It was positioned with the rotation mechanism on the upstream side, to ensure better protection against hadronic showers during beam impacts and shock waves travelling through the jaws which might cause damage. A photograph of HRMT-21 in the tunnel showing the location of the radiation-hard camera is shown in Fig. 12.

\section{B. Instrumentation}

The HiRadMat facility is already equipped with BLMs, BPMs and a beam television (BTV)/beam position stripline pick-up (BPKG) for transverse beam profile and position measurements. Some additional instrumentation was procured specifically for the HRMT-21 experiment. As this first generation prototype did not include a direct readout of the jaw rotation angle, accelerometers were placed near the rotation mechanism on the upstream side of the collimator to detect the vibrations resulting from physical contact when the claw hooks the wheel teeth. If the 


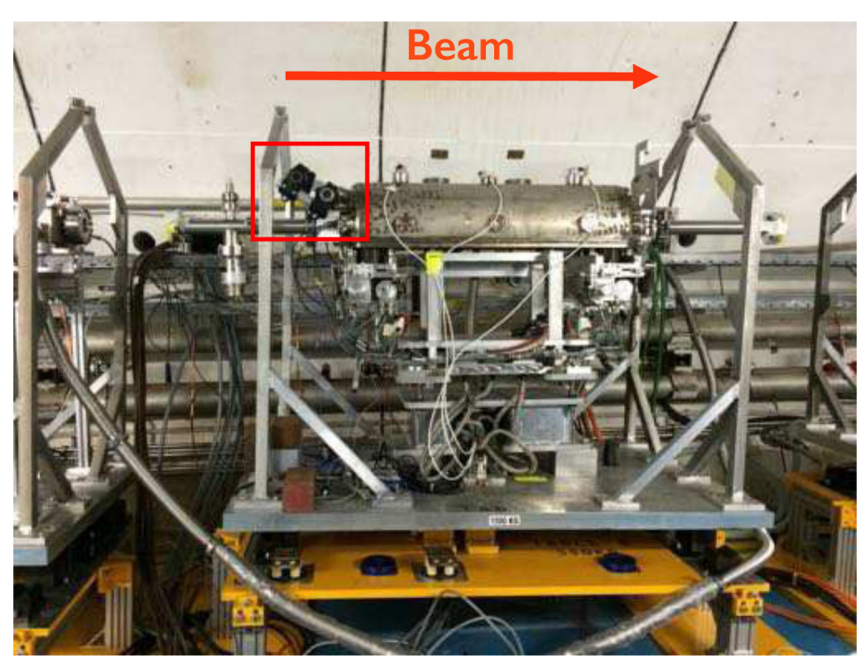

FIG. 12. Installation of the rotatable collimator prototype on the HiRadMat experimental table in the tunnel, showing the beam direction and the location of the radiation-hard camera.

jaws are initially parallel (which was established on surface prior to the beam test), then each detected vibration or "click" (with an amplitude above some preestablished threshold) would correspond to a 1/48 turn of the wheel. After 384 clicks are detected ( 8 rotations of the wheel), the jaw would have rotated by one facet $(1 / 20$ th of a revolution or $18^{\circ}$ ). Two accelerometers were placed on each jaw, and the locations were selected based on criteria including click detection quality, ease of access and probability of remaining attached with glue throughout the transport, tunnel installation and experiment.

A radiation-hard camera was used to record any damage sustained following each beam impact, and provide a visual check of the rotation status over time. Thermal probes were connected to each of the four jaw corners. A static pressure sensor was used to monitor the pressure inside the cooling pipes of the collimator tank, which were partly filled with water. The collimator BPMs were removed for the tests. A schematic overview showing the locations of the sensors installed for the HiRadMat beam tests is shown in Fig. 13, and a summary of the different types of instrumentation used is shown in Table II.

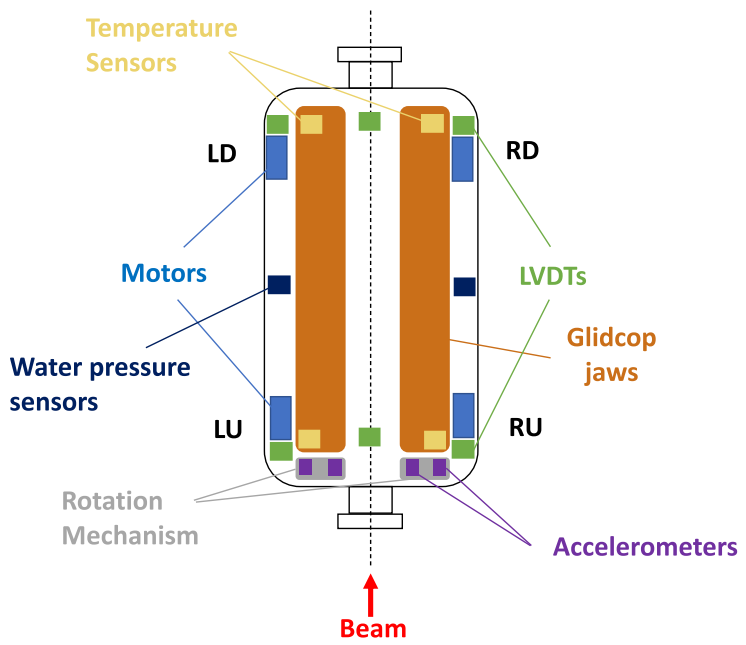

FIG. 13. Schematic overview of the rotatable collimator prototype showing the sensors installed for the HiRadMat beam damage tests.

\section{Beam parameters and pulse list}

The beam pulse list used in the experiment is shown in Table III. Based on analytic calculations and the experience with previous experiments (e.g., [30,31]), the first three shots should be below or at the onset of plastic damage, which is estimated to be around $2 \times 10^{12} \mathrm{p}$ at $440 \mathrm{GeV}$, i.e., $141 \mathrm{~kJ}$. The fourth shot is an intermediary shot, while the following two shots should correspond to the design failure for the rotatable collimator prototype at $7 \mathrm{TeV}\left(1.5 \times 10^{13} \mathrm{p}\right.$ at $440 \mathrm{GeV}$, i.e., $\left.1 \mathrm{MJ}\right)$. The final two shots correspond to a HL-LHC injection error, with an energy deposition of $2.4 \mathrm{MJ}\left(3.5 \times 10^{13} \mathrm{p}\right.$ at $\left.440 \mathrm{GeV}\right)$. In the case of the second shot, the transverse beam size was reduced to the minimum possible value to test the collimator with the ultimate set of parameters. These 8 shots, together with the low intensity alignment shots, correspond to a cumulative total energy deposition of $1.175 \times 10^{14} \mathrm{p}$. At the end of the beam tests, both jaws were rotated until they had exceeded one revolution each, to stress test the cooling pipes.

TABLE II. Main characteristics of the instrumentation used in the experiment.

\begin{tabular}{|c|c|c|c|c|}
\hline Sensor type/equipment & Specification & Quantity & Acquisition range & $\begin{array}{l}\text { Sampling } \\
\text { frequency }\end{array}$ \\
\hline Position sensor (LVDT) & HCA 2000 & 7 & -7 to $60 \mathrm{~mm}$ & $1 / 100 \mathrm{~Hz}$ \\
\hline Jaw temperature sensor & PT100 & 4 & $-200^{\circ} \mathrm{C}$ to $650^{\circ} \mathrm{C}$ & $1 \mathrm{~Hz}$ \\
\hline Water pressure sensor & IPS & 2 & -1 to 400 bar & $10 \mathrm{~Hz}$ \\
\hline Stepper motor & Maccon SM 87 & 4 & -7 to $30 \mathrm{~mm}$ & $1 \mathrm{~Hz}$ \\
\hline Accelerometer & PCB 357B11 & 4 & $\pm 22600 \mathrm{~ms}^{-2} \mathrm{pk}$ & $1.2 \mathrm{kHz}$ \\
\hline Radiation-hard camera & $\begin{array}{c}\text { ThermoFisher } \\
\text { CID8825D }\end{array}$ & 1 & Color $(710 \times 484)$ & 30 frames/s \\
\hline $\mathrm{BTV} / \mathrm{BPKG}$ & $\ldots$ & 1 & $0.1<\sigma<1.5 \mathrm{~mm}$ & Single shot \\
\hline
\end{tabular}


TABLE III. Pulse list used in the HRMT-21 beam test, showing the impacted jaw and the number of facets rotated in each case.

\begin{tabular}{|c|c|c|c|c|c|c|c|c|}
\hline \multirow[b]{2}{*}{ No. } & \multirow{2}{*}{$\begin{array}{l}\text { No. of } \\
\text { bunches }\end{array}$} & \multicolumn{2}{|c|}{ Intensity [p] } & \multirow{2}{*}{$\begin{array}{l}\text { Spot size } \\
{[\mathrm{mm}]}\end{array}$} & \multirow{2}{*}{$\begin{array}{c}\text { Pulse } \\
\text { length }[\mu \mathrm{s}]\end{array}$} & \multirow[b]{2}{*}{ Task } & \multirow{2}{*}{$\begin{array}{l}\text { Impacted } \\
\text { Jaw }\end{array}$} & \multirow{2}{*}{$\begin{array}{c}\text { Energy } \\
{[\mathrm{kJ}]}\end{array}$} \\
\hline & & per bunch & Total & & & & & \\
\hline $1-36$ & 1 & $5.0 \times 10^{10}$ & $1.8 \times 10^{12}$ & 0.35 & 0.025 & Alignment & & \\
\hline 37 & 4 & $1.2 \times 10^{11}$ & $4.8 \times 10^{11}$ & 0.35 & 0.1 & $\begin{array}{c}\text { Shot No. } 1 \\
\text { Left jaw rotation, } 1 \text { facet }\end{array}$ & Left & 33.8 \\
\hline $38-56$ & 1 & $5.0 \times 10^{10}$ & $9.0 \times 10^{11}$ & 0.35 & 0.025 & Alignment & & \\
\hline 57 & 12 & $1.2 \times 10^{11}$ & $1.44 \times 10^{12}$ & 0.35 & 0.3 & $\begin{array}{c}\text { Shot No. } 2 \\
\text { Left jaw rotation, } 1 \text { facet }\end{array}$ & Left & 101.4 \\
\hline $58-77$ & 1 & $5.0 \times 10^{10}$ & $9.5 \times 10^{11}$ & 0.35 & 0.025 & Alignment & & \\
\hline 78 & 24 & $1.2 \times 10^{11}$ & $2.88 \times 10^{12}$ & 0.35 & 0.6 & $\begin{array}{c}\text { Shot No. } 3 \\
\text { Left jaw rotation, } 1 \text { facet } \\
\text { Right jaw rotation, } 1 \text { facet }\end{array}$ & Left & 202.8 \\
\hline $79-115$ & 1 & $5.0 \times 10^{10}$ & $1.8 \times 10^{12}$ & 0.35 & 0.025 & Alignment & & \\
\hline 116 & 48 & $1.2 \times 10^{11}$ & $5.76 \times 10^{12}$ & 0.35 & 1.2 & $\begin{array}{l}\text { Shot No. } 4 \\
\text { Left jaw rotation, } 1 \text { facet } \\
\text { Right jaw rotation, } 1 \text { facet }\end{array}$ & Left & 405.5 \\
\hline $117-153$ & 1 & $5.0 \times 10^{10}$ & $1.8 \times 10^{12}$ & 0.35 & 0.025 & Alignment & & \\
\hline 154 & 72 & $1.2 \times 10^{11}$ & $8.64 \times 10^{12}$ & 0.35 & 1.8 & $\begin{array}{l}\text { Shot No. } 5 \\
\text { Left jaw rotation, } 5 \text { facets } \\
\text { Right jaw rotation, } 3 \text { facets }\end{array}$ & Left & 608.3 \\
\hline $155-191$ & 1 & $5.0 \times 10^{10}$ & $1.8 \times 10^{12}$ & 0.35 & 0.025 & Alignment & & \\
\hline 192 & 144 & $1.2 \times 10^{11}$ & $1.73 \times 10^{13}$ & 0.35 & 3.6 & $\begin{array}{l}\text { Shot No. } 6 \\
\text { Left jaw rotation, } 2 \text { facets } \\
\text { Right jaw rotation, } 2 \text { facets }\end{array}$ & Left & 1218 \\
\hline $193-211$ & 1 & $5.0 \times 10^{10}$ & $9.0 \times 10^{11}$ & 0.35 & 0.025 & Alignment & & \\
\hline 212 & 288 & $1.2 \times 10^{11}$ & $3.46 \times 10^{13}$ & 0.35 & 7.2 & $\begin{array}{l}\text { Shot No. } 7 \\
\text { Left jaw rotation, } 3 \text { facets } \\
\text { Right jaw rotation, } 2 \text { facets }\end{array}$ & Right & 2436 \\
\hline $213-249$ & 1 & $5.0 \times 10^{10}$ & $1.8 \times 10^{12}$ & 0.25 & 0.025 & Alignment & & \\
\hline 250 & 288 & $1.2 \times 10^{11}$ & $3.46 \times 10^{13}$ & 0.25 & 7.2 & $\begin{array}{c}\text { Shot No. } 8 \\
\text { Left jaw rotation, } 2 \text { facets } \\
\text { Right jaw rotation, } 13 \text { facets }\end{array}$ & Left & 2436 \\
\hline
\end{tabular}

\section{Irradiation test results}

A beam-based alignment was performed before every shot to determine the beam center at the collimator position. Low intensity bunches of $5 \times 10^{10} \mathrm{p}$ were shot into the collimator. The procedure adopted was to move the jaw in $100 \mu \mathrm{m}$ steps for each shot and record the BLM signal and the beam current transformer (BCT) intensity. After plotting the BLM signal normalized to the BCT signal (normalized beam loss) for each jaw position, the Gaussian cumulative density function (CDF) should be obtained. If the procedure is repeated with the other jaw, then the two CDFs should intersect at the beam center, at the halfway point of the CDF.

At the start of the experiment, an initial beam-based alignment was performed, as shown in Fig. 14. It should be noted that the curves obtained for the left and right jaws do not intersect. In addition, when closing both jaws, an anticollision switch should trigger at about $0.3 \mathrm{~mm}$ to prevent the jaws from hitting each other. Instead, the switch was activated at a gap of $4 \mathrm{~mm}$, indicating an issue with the absolute positioning of the jaws. As a $3 \mathrm{~mm}$ discrepancy was found between the alignment curves of the two jaws, during the shots the gap was set to $8 \mathrm{~mm}$ instead of $5 \mathrm{~mm}(8 \mathrm{~mm}$ is the gap in $\mathrm{mm}$ corresponding to a $7 \sigma$ half gap).

An angular alignment was then performed in order to determine whether any tilts were present along the longitudinal axis in the collimator tank. The beam-based alignment is performed for various jaw tilts, each time keeping the jaws parallel to one another, as shown in Fig. 15. The minimum of the fitted polynomial (of the form $y=a x^{2}+$ $b x+c)$ gives the angle which the jaws would need to be positioned to be truly parallel to the beam. As the angle determined ( $~ 500 \mu \mathrm{rad})$ is small compared to the jaw and angle step sizes, it was decided not to apply any tilt in the jaws for the experiment.

A summary of the observations noted for each shot is shown in Table IV. Debris was observed from shot 4 


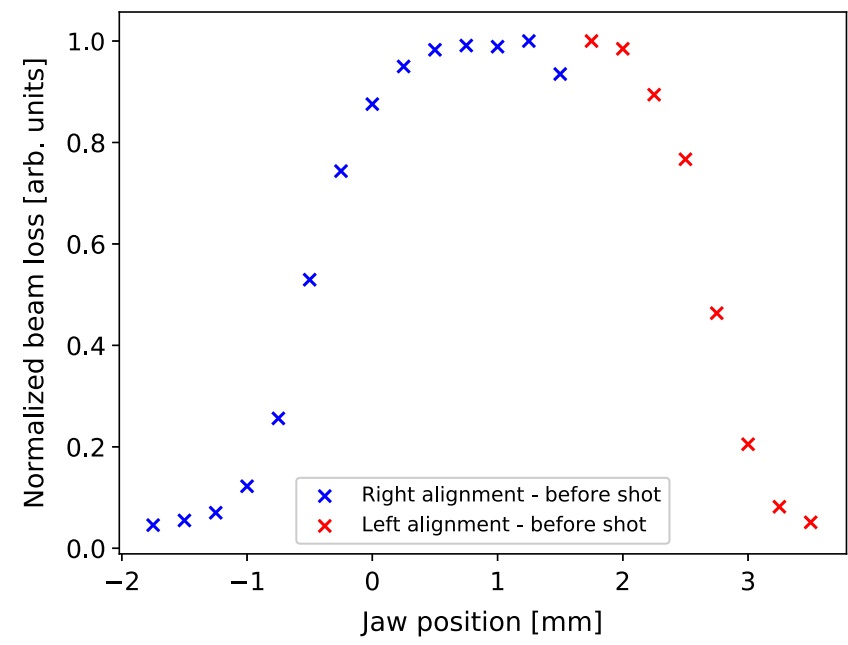

FIG. 14. Results from the collimator beam-based alignment performed at the start of the experiment.

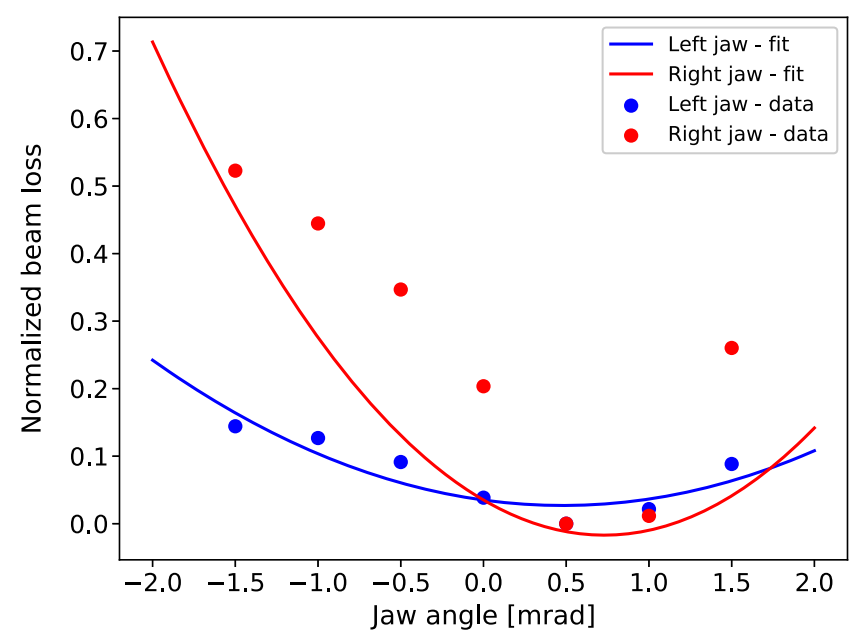

FIG. 15. Beam-based angular alignment.

(pulse 116) onwards, and even though films of Glidcop appeared to stick to the other jaw, no jaw welding was noted, and it was possible to open the jaws back to parking positions normally. The $1 \sigma$ beam size measured by the

TABLE IV. Summary of observations for each shot in the experiment.

\begin{tabular}{lcl}
\hline \hline Shot no. & Pulse no. & \multicolumn{1}{c}{ Comments } \\
\hline 1 & 37 & No damage noted \\
2 & 57 & No damage noted \\
3 & 78 & First damage noted \\
4 & 116 & Copper debris accumulation, right jaw \\
5 & 154 & Peeling off of copper film on right jaw \\
6 & 192 & Molten copper, part of jaw \\
7 & 212 & Molten copper, full length of jaw \\
8 & 250 & Molten copper, full length of jaw \\
\hline \hline
\end{tabular}

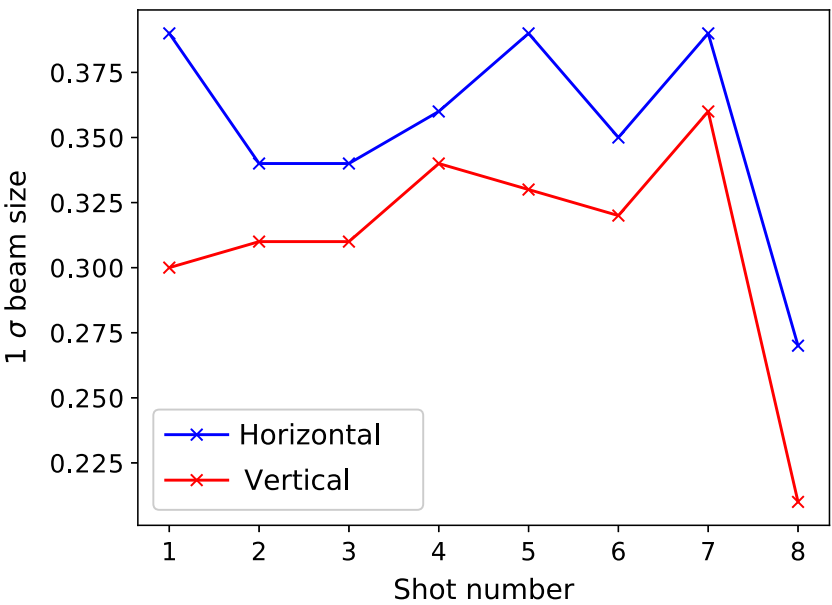

FIG. 16. The horizontal and vertical beam sizes measured with the BTV-BPKG during each of the high-intensity pulses in the experiment.

BTV-BPKG for each shot is shown in Fig. 16. During the postirradiation right jaw rotation, although the jaw initially rotated by a few steps, the angular movement then ceased altogether. The amount by which jaw moves in across the inner switch had to be increased by $100 \mu \mathrm{m}$ to ensure that the claw engages the ratchet, and it was possible to resume the rotations. Therefore, the rotation functionality was deemed to be a success, given that it withstood a
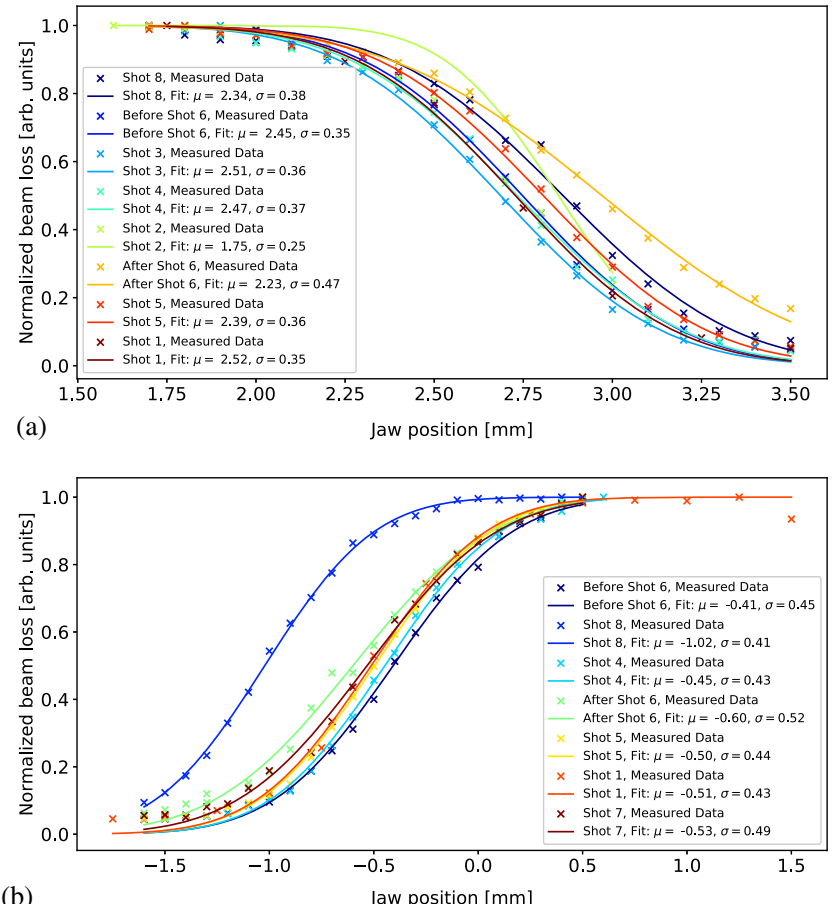

(b)

FIG. 17. Gaussian CDF fits to the normalized beam loss as a function of the left and right jaw positions measured during all alignments throughout the test. (a) Left jaw alignments and (b) Right jaw alignments. 


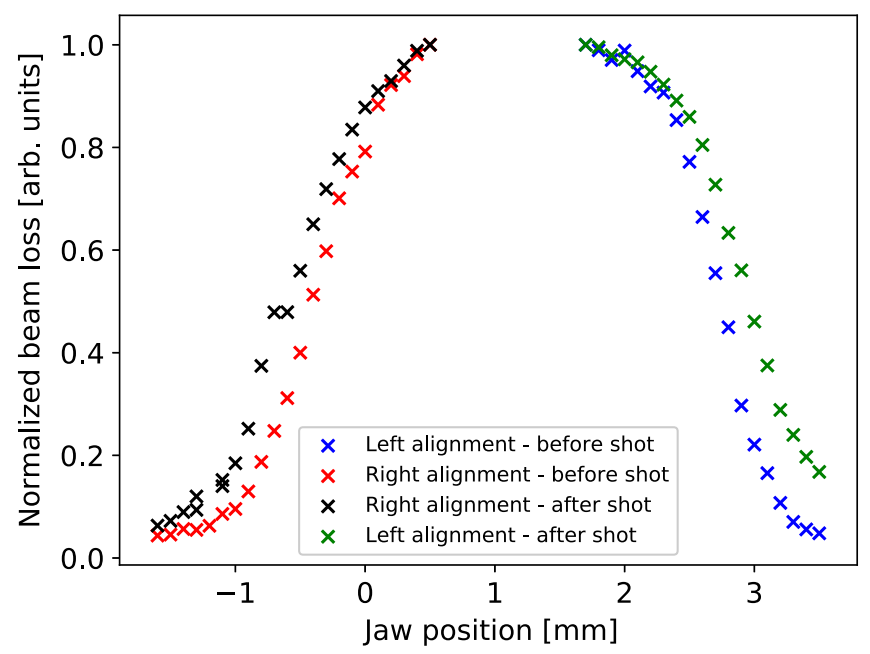

FIG. 18. Comparison of the left and right jaw alignments before and after shot 6 (pulse 192), showing the effect of the subsequent debris on the measured jaw positions.

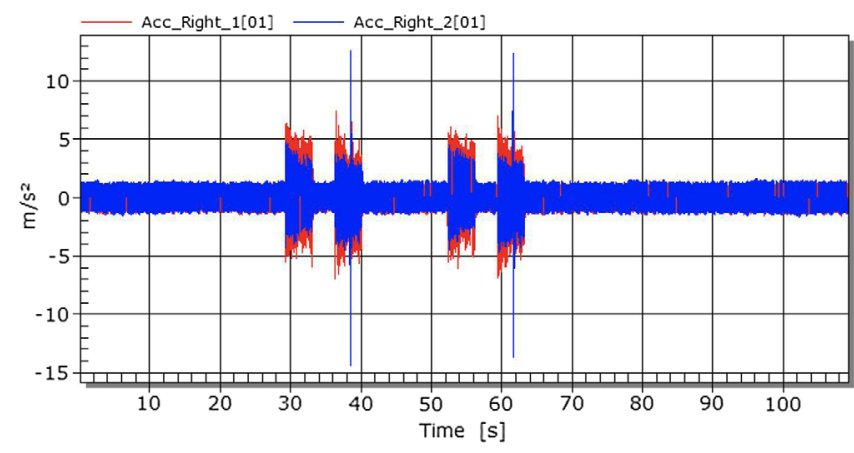

FIG. 19. Accelerometer measurements during a right jaw rotation. A click is detected if the reading exceeds a certain threshold, e.g., $8 \mathrm{~ms}^{-2}$.

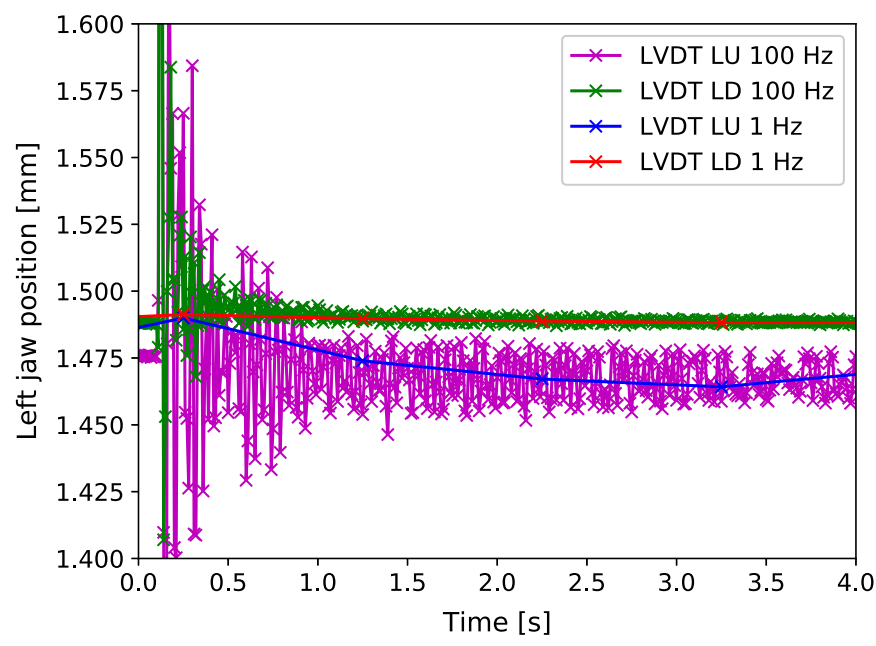

FIG. 20. Left jaw positions measured by the LVDT sensors during shot 8 (pulse 250). The $100 \mathrm{~Hz}$ and $1 \mathrm{~Hz}$ data acquisitions are superimposed and synchronized in time.

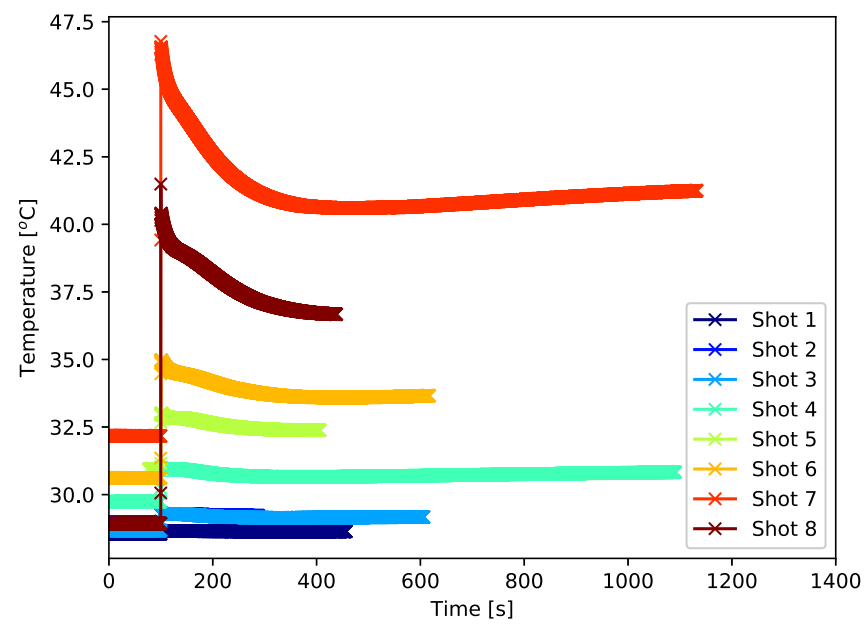

FIG. 21. Temperature measurements acquired from the leftupstream jaw corner probe during the eight shots, superimposed over each other and synchronized in time.

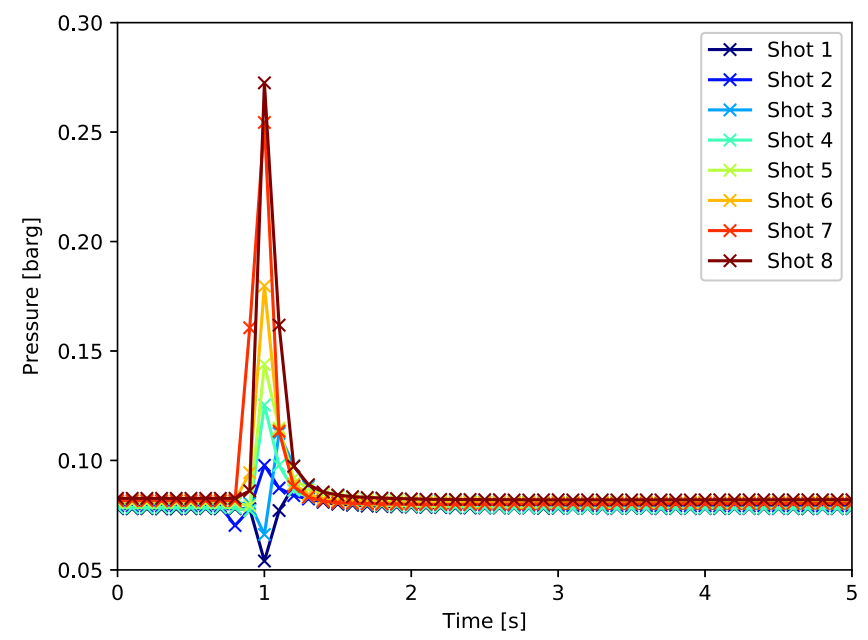

FIG. 22. Pressure measurements acquired during the eight shots, superimposed over each other and synchronized in time.

catastrophic damage scenario well beyond what was foreseen for the design.

The results from the beam-based alignments performed throughout the experiment, together with Gaussian CDF fits applied, are shown in Fig. 17. The most evident discrepancy among the curves is that of the alignment performed for the right jaw before shot 8 (pulse 250). This jaw had just been subjected to a 288 bunch impact (shot 7; pulse 212), which has had an effect on the mechanics and positioning of the jaw. Note that this scenario corresponds to more than a factor 2 higher energy than the intended design case. In addition, a comparison of the left and right jaw alignments before and after shot 6 (pulse 192) shown in Fig. 18 illustrates the effect of the subsequent debris on the measured jaw positions.

The accelerometer measurements recorded during a right jaw rotation are shown in Fig. 19. The data acquisition 


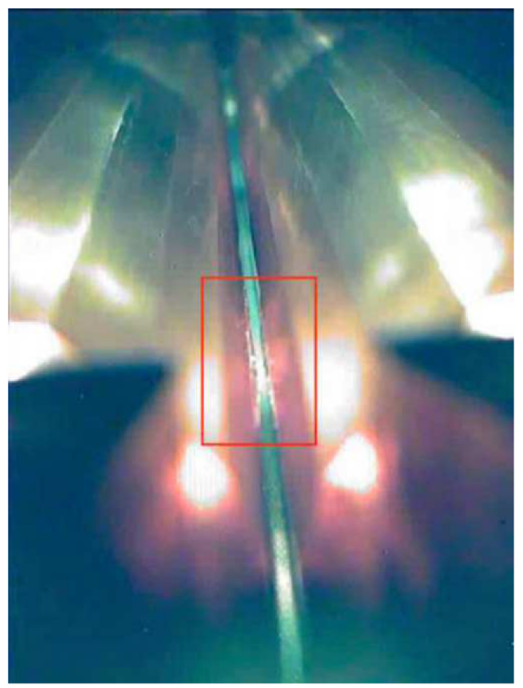

(a)

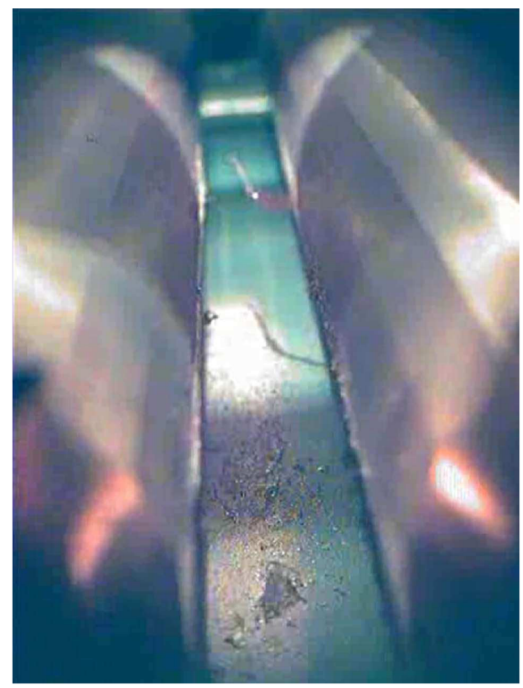

(b)

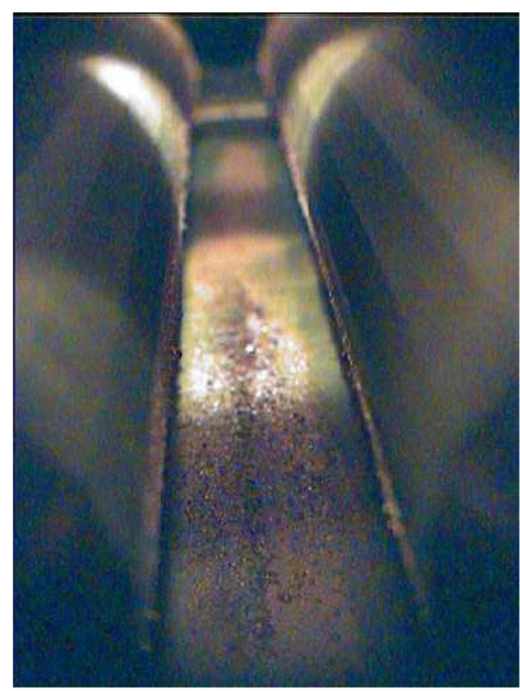

(c)

FIG. 23. Stills taken from the video stream during various instances through the HRMT-21 experiment. In each case, the beam enters the collimator from the bottom of the photograph. (a) First indication of localized damage (red box) at shot 3 (pulse 78) with 24 bunches and jaws at operational positions, (b) Debris observed after opening the jaws to parking positions after shot 5 (pulse 154) with 72 bunches, and (c) Debris observed along the full jaw length after opening the jaws to parking positions (shot 7, pulse 212,288 bunches).

software could count the number of "clicks" by applying a suitable threshold on the reading. It was not possible to compare the vibration measurements from the accelerometers to the LVDT vibration readings shown earlier, as the acquisition was set up in terms of sampling rate to detect clicks during jaw rotation.

In order to appreciate the vibrations of the jaws when impacted by the beam, LVDT measurements of the jaw corner positions are shown in Fig. 20. The data for shot 8 (pulse 250) are displayed, as the $100 \mathrm{~Hz}$ acquisition and logging was only enabled for the final shot. The temperature measurements acquired during each shot, for the left and right upstream jaw corners, are shown in Fig. 21. The curves are synchronized to start from the same point in time. Similarly, water pressure measurements are shown in Fig. 22. Finally, a selection of stills from the video recording of the radiation-hard camera, representing some the main highlights in the experiment, are shown in Fig. 23.

The damage results seen in these experiments are consistent with those obtained in the earlier material study experiments performed in the HiRadMat test area [30,31]. The damage threshold is $\sim 200 \mathrm{~kJ}$ and the extent of damage is of the order of $10 \mathrm{~cm}$ in length and $2 \mathrm{~mm}$ in width. Outside the melting region, the thermal shock of the beam impact causes instantaneous temperature changes of around $25^{\circ} \mathrm{C}$ (Fig. 21), and an increase in the pressure of the water cooling circuit of around 0.25 barg (Fig. 22). The ejecta from the damaged region seems to have been contained within the $2 \mathrm{~cm}$ facet width, the cooling circuit was robust against the beam-induced pressure spike and the rotation mechanism functioned for a full lifetime of 20 -facet turns despite the ejecta, temperature spike and mechanical shock suffered during 8 test shots. Thus, at a certain level, the design concept of a rotatable collimator is validated. After radiation cool-down, the jaws will be examined for permanent deformation and more detailed measurements of damage extent made. A non-LHC specific rotatable collimator design would allow for improvements in many areas, notably the rotation drive and angular readout of jaw position.

\section{CONCLUSIONS}

Beam collimation and cleaning systems are of vital importance in high-energy, high-intensity particle accelerators to ensure safe operation. Given that beam impacts (such as those resulting from an asynchronous beam dump) comprise a catastrophic scenario for collimators in the LHC, a rotatable collimator design was developed at SLAC to avoid potential collimator replacements, which would result in significant downtime. The design follows the concept of a disposable jaw, with a round design featuring 20 facets that can be exchanged after destructive beam impact, and enables the usage of conventional low-impedance absorbing materials. A rotatable collimator prototype was built and tested with circulating beam in the SPS, and then subjected to destructive beam tests in HiRadMat.

The present HL-LHC upgrade baseline relies on a strategy based on sufficiently-robust low-impedance materials mounted on the more conventional LHC design with integrated BPMs. The need for fast and regular collimator beam-based alignment enabled by integrated BPMs was another motivation in the choice for the HL-LHC collimator design and the decision to not adopt the rotatable 
collimator design for the HL-LHC. The latest secondary collimator design based on new materials fulfills all the design requests in terms of impedance and robustness, covering also the more-demanding case of injection failures. The rotatable collimator design remains a very promising option for future machines and upgrades and was studied in detail to identify possible improvements for future implementations, for example cases where the high $\mathrm{Z}$ absorber is sacrificed as it absorbs beam energy to protect downstream components.

Installing the rotatable collimator prototype in an operating accelerator like the SPS was a key milestone. It demonstrated that this device was built respecting the accelerator quality requirements for ultrahigh vacuum machines. In fact, from the vacuum and impedance view points it could also have been installed in the LHC, but the deployment in the SPS was preferred because it could be carried out in a short technical stop in the middle of the run, contrary to the LHC that would have required a long stop. The measurements carried out validated successfully the main operational aspects of this design. Preliminary impedance measurements were also performed through tune shift measurements versus collimator gap movement: the tune shift was confirmed to be at least below the measurement resolution of $\sim 10^{-4}$. In all the aspects tested, the operational performance can considered equivalent to that of a standard LHC collimator.

The rotation functionality was deemed to be a success, given that it withstood a catastrophic damage scenario beyond what was foreseen in the design for the $7 \mathrm{TeV}$ case. In addition, no issues were observed with the cooling circuit following two full revolutions performed by each jaw. However, although the beam tests provided an excellent validation of the collimator design, it was evident that the propagation of ejecta from the impacted jaw down the beam pipe could potentially affect vacuum conditions for future operation. Therefore, this needs to be studied in greater detail to better quantify the negative effects of such a catastrophic scenario.

The prototype developed by SLAC for LHC use was constrained by the LHC beam pipe geometry and optimized for LHC beam power, running conditions and foreseeable accident conditions as a direct length-constrained possible replacement for a presently installed LHC carbon collimator. These tests show that the rotatable collimator satisfied the cooling requirements imposed by DC and temporary injection-related beam losses, absorbing beam and protecting downstream components while surviving the accidental $1 \mathrm{MJ}$ beam abort accident scenario. A second generation design would improve details shown to be problematic in these tests, notably angular read back and mechanical tolerances on the drive mechanism. The rotatable collimator concept could be extended to other applications, particularly those that would allow more transverse space for larger diameter collimating cylinders, for example in transfer lines or linear accelerators.

\section{ACKNOWLEDGMENTS}

This research was supported by the EU FP7 EuCARD-2 project (Grant agreement No. 312453), the EU FP7 HiLumi LHC study (Grant Agreement No. 284404), the EU Horizon 2020 ARIES project (Grant Agreement No. 730871), the HL-LHC project, the Department of Energy Contract No. DE-AC02-76SF00515 and the U.S. LHC Accelerator Research Program (LARP). The authors would like to acknowledge the efforts of several people at SLAC and CERN who contributed to the design, validation and beam tests of the rotatable collimator prototype. In particular, A. Fabich, F. Harden, A. Bouvard and Y. Kadi who helped out with the coordination of the HiRadMat experiment, G. Baud, M. Gasior and J. Olexa as well as S. Jackson, C. Zamantzas for support with the BPM and BLM data acquisitions in the SPS, respectively, J.-F. Fuchs and M. Tortrat who were part of the survey team who performed the alignment, S. De Man, P. Françon and I. Lamas Garcia for the preparation of the collimator for installation in the SPS and HiRadMat test facility, G. Cattenoz who performed the vacuum tests, R. Rossi and E. Quaranta from the collimation team for support during the SPS beam tests, B. Salvant, E. Métral, O. Berrig, J. Kuczerowski, A. Mostacci, F. Caspers from the CERN impedance group, L. Xiao from the SLAC impedance group, M. Donze and A. Masi for support with the collimator control system, M. Calviani for support with the radiation hard camera, K. Weiss from the Radiation Protection group, and the SPS operators O. Andujar, S. Cettour Cave, J. Dalla-Costa, F. Follin, S. Massot, E. Veyrunes and C. Wetton.

[1] O. Brüning, P. Collier, P. Lebrun, S. Myers, R. Ostojic, J. Poole, and P. Proudlock, LHC Design Report Vol. 1: The LHC Main Ring, 2004, CERN-2004-003-V1.

[2] I. Bejar Alonso et al., HiLumi LHC Technical Design Report, Technical report, CERN-ACC-2015-0140, 2015.

[3] R. W. Assmann et al., The final collimation system for the LHC, in Proceedings of the 10th European Particle Accelerator Conference, Edinburgh, Scotland, 2006 (EPSAG, Edinburgh, Scotland, 2006).

[4] S. Redaelli, Beam Cleaning and Collimation Systems, in Proceedings, 2014 Joint International Accelerator School: Beam Loss and Accelerator Protection: Newport Beach, CA, USA, November 5-14, 2014, pp. 403-437, 2016.

[5] L. Lari, Beam-machine interaction studies for the Phase II LHC collimation system, EPFL Report No. CERNTHESIS-2010-207, 2010.

[6] R. Bruce, R. W. Assmann, and S. Redaelli, Calculations of safe collimator settings and $\beta^{*}$ at the CERN Large Hadron Collider, Phys. Rev. Accel. Beams 18, 061001 (2015).

[7] E. Quaranta, A. Bertarelli, R. Bruce, F. Carra, F. Cerutti, A. Lechner, S. Redaelli, E. Skordis, and P. Gradassi, Modeling of beam-induced damage of the LHC tertiary collimators, Phys. Rev. Accel. Beams 20, 091002 (2017). 
[8] R. Bruce, C. Bracco, R. De Maria, M. Giovannozzi, A. Mereghetti, D. Mirarchi, S. Redaelli, E. Quaranta, and B. Salvachua, Reaching record-low $\beta^{*}$ at the CERN Large Hadron Collider using a novel scheme of collimator settings and optics, Nucl. Instrum. Methods Phys. Res., Sect. A 848, 19 (2017).

[9] I. Efthymiopoulos et al., HiRadMat: a new irradiation facility for material testing at CERN, in Proceedings of the 2nd International Particle Accelerator Conference (JACoW, Geneva, 2011), pp. 1665-1667.

[10] T. Markiewicz et al., Construction and bench testing of a prototype rotatable collimator for the LHC, in Proceedings of the 5th International Particle Accelerator Conference (JACoW, Geneva, 2014), pp. 178-181.

[11] J. Claiborne Smith et al., Design of a rotatable copper collimator for the LHC Phase II Collimation Upgrade, in Proceedings of the 11th European Particle Accelerator Conference (JACoW, Geneva, 2008), pp. 289-291.

[12] J. Claiborne Smith et al., Mechanical and thermal prototype testing for a rotatable collimator for the LHC Phase II collimation upgrade, in Proceedings of the 11th European Particle Accelerator Conference (JACoW, Geneva, 2008), pp. 286-288.

[13] K. Yokoya, Impedance of slowly tapered structures, CERN Technical Report No. CERN-SL-90-88-AP, 1988.

[14] J. Claiborne Smith et al., Bench-top impedance measurements for a rotatable copper collimator for the LHC Phase II collimation upgrade, in Proceedings of the 11th European Particle Accelerator Conference (JACoW, Geneva, 2008), pp. 1703-1705.

[15] J. Claiborne Smith et al., BPM design and impedance considerations for a rotatable collimator for the LHC collimation upgrade, in Proceedings of the 1st International Particle Accelerator Conference (JACoW, Geneva, 2010), pp. 1704-1706.

[16] A. Dallocchio et al., LHC collimators with embedded beam position monitors: a new advanced mechanical design, in Proceedings of the 2nd International Particle Accelerator Conference (JACoW, Geneva, 2011), pp. 1611-1613.

[17] J. Claiborne Smith et al., Recent progress on the design of a rotatable copper collimator for the LHC collimation upgrade, in Proceedings of the 23rd Particle Accelerator Conference (JACoW, Geneva, 2009), pp. 2853-2855.

[18] J. Claiborne Smith et al., Construction and bench testing of a rotatable collimator for the LHC collimation upgrade, in Proceedings of the 1st International Particle Accelerator Conference (JACoW, Geneva, 2010), pp. 1701-1703.

[19] L. Xiao et al., Longitudinal wakefield study in SLAC rotatable collimator design for the LHC Phase II upgrade, in Proceedings of the 1st International Particle Accelerator Conference (JACoW, Geneva, 2010), pp. 1898-1900.

[20] T. Weiler et al., LHC collimation system hardware commissioning, in Proceedings of the Particle Accelerator Conference (JACoW, Geneva, 2007), pp. 1625-1627.

[21] D. Wollmann et al., First beam results for a collimator with in-jaw beam position monitors, in Proceedings of the 2 nd International Particle Accelerator Conference (JACoW, Geneva, 2011), pp. 3747-3749.

[22] S. Redaelli et al., The LHC collimator controls architecturedesign and beam tests, in Proceedings of the Particle Accelerator Conference (JACoW, Geneva, 2007), pp. 344-346.

[23] M. Arruat et al., Front-end software architecture, in Proceedings of ICALEPCS (JACoW, Geneva, 2007), pp. 310-312.

[24] M. Gasior, R. J. Steinhagen, and J. Olexa, BPM electronics based on compensated diode detectors-results from development systems, in Proceedings of the Beam Instrumentation Workshop (JACoW, Geneva, 2012), pp. 44-46.

[25] G. Valentino, A. A. Nosych, R. Bruce, M. Gasior, D. Mirarchi, S. Redaelli, B. Salvachua, and D. Wollmann, Successive approximation algorithm for beam-positionmonitor-based LHC collimator alignment, Phys. Rev. Accel. Beams 17, 021005 (2014).

[26] G. Valentino, R. Aßmann, R. Bruce, S. Redaelli, A. Rossi, N. Sammut, and D. Wollmann, Semiautomatic beam-based LHC collimator alignment, Phys. Rev. Accel. Beams 15, 051002 (2012).

[27] N. Mounet, The LHC transverse coupled-bunch instability, EPFL Lausanne Report No. CERN-THESIS-2012-055, 2012.

[28] M. Cauchi et al., High energy beam impact tests on a LHC tertiary collimator at the CERN high-radiation to materials facility, Phys. Rev. Accel. Beams 17, 021004 (2014).

[29] F. Carra, Thermomechanical response of advanced materials under quasi-instantaneous heating, Ph.D. thesis, Politecnico di Torino, 2017.

[30] A. Bertarelli et al., An experiment to test advanced materials impacted by intense proton pulses at CERN HiRadMat facility, Nucl. Instrum. Methods Phys. Res., Sect. B 308, 88 (2013).

[31] A. Bertarelli et al., Dynamic testing and characterization of advanced materials in a new experiment at CERN HiRadMat facility, in Proceedings of the 9th International Particle Accelerator Conference (JACoW, Geneva, 2018), pp. 2534-2537. 